\title{
Compacting Properties of Zeolite Based Warm Asphalt Mixture
}

\author{
Liying Yang ${ }^{1, a}$, Yiqiu Tan ${ }^{1, b}$ \\ ${ }^{1}$ School of Transportation Science and Engineering, Harbin Institute of Technology, \\ Haihe road 202\#, Harbin, Heilongjiang, China 150090 \\ ${ }^{2}$ Beijing Municipal Road \& Bridge Building Material Group Co.Ltd, \\ West of Wanglizhuang Railway Bridge, Daxing District, Beijing, China, 102600 \\ ayangliying_q@sina.com, ’yiqiutan@163.com
}

\section{Key words: Warm Asphalt Mix, Zeolite, Compaction Properties, Performance}

\begin{abstract}
Warm asphalt mixture develops rapidly throughout the world in recent years. Zeolite based warm mix is one of the warm mixtures. In this paper, seven kinds of zeolites including six natural zeolites and one synthetic zeolite are selected. As warm mix additives, their physical properties such as density, water content and pore arrangements are tested respectively. To evaluate the compacting properties of zeolites based warm asphalt mixture, AC-20 mixture is designed and compaction is conducted. It shows that zeolites can reduce the compacting temperature for both Marshall and gyratory compaction. Temperature is the main factors which influence the compaction effect. Type of zeolite affects compaction to some extent. Marshall compaction is more sensitive to zeolite than gyratory compaction.
\end{abstract}

\section{Introduction}

Warm asphalt mixture is a new technology. It can reduce the mixing temperature for about $30^{\circ} \mathrm{C}$ and thus decrease the energy consumption and lower the emission. The performance of the mixture is equivalent to its hot counterpart. There are four types of warm mix: Aspha-Min, WAM-Foam, organic additives and asphalt emulsion[1]. Aspha-min is a synthetic zeolite.

Zeolite is a group of alumino-silicates. Its unique character is the internal mineral skeleton which is a group of interconnected tetrahedrons. A silicon ion lies in the center which is surrounded by four oxygen atoms. The silicon-oxygen arrangement $\left(\mathrm{SiO}_{4}\right)$ forms a tetrahedron with four oxygen ions at the four top points. The silicon icon can be replaced by aluminum and an aluminum-oxygen tetrahedron forms. All these tetrahedrons interconnect, to form the zeolite skeleton. In the skeleton, there are many kinds of pores and tunnels with different size and shape. The porous zeolite contains certain amount of water of crystallization. The water will evaporate gradually with the increasing temperature, which leads to foaming in asphalt. The foams increase the binder volume and reduce the viscosity of the binder to improve the workability [2].

To evaluate the compacting properties of zeolite based warm mix, seven zeolites are selected and tested. AC-20 asphalt mixture is designed and the compacting behavior is researched.

\section{Zeolites}

Seven Zeolite samples including six natural zeolites and one synthetic zeolite are selected. The natural zeolites are taken from quarries of Heibei, Henan and Liaoning Provinces. The synthetic zeolite is Aspha-min. 
Density. Density is the most fundamental property of mineral additives. Table 1 is the apparent density of zeolites. No.1 to No.6 is the 6 kinds of natural zeolites and No.7 is the synthetic product. The apparent density of all zeolites is far smaller than that of limestone filler. No.1 has the lowest density, while No. 6 has the highest. The density is mainly determined by their origin.

Table 1 Apparent density of zeolites and limestone filler

\begin{tabular}{ccccccccc}
\hline Zeolite & 1 & 2 & 3 & 4 & 5 & 6 & 7 & filler \\
\hline Apparent density $\left(\mathrm{g} / \mathrm{cm}^{3}\right)$ & 2.127 & 2.375 & 2.145 & 2.294 & 2.223 & 2.623 & 2.297 & 2.811 \\
\hline
\end{tabular}

Pore structure. Zeolite is a porous mineral. The large amount of pore provides enough space for water. With Mercury porosimetry test[3], the pore size and distribution of zeolites are tested and the result is listed in Table 2.

Table 2 Pore structure of zeolites

\begin{tabular}{cccc}
\hline Zeolite & $\begin{array}{c}\text { Median pore diameter } \\
(\mathrm{nm})\end{array}$ & $\begin{array}{c}\text { Average pore diameter } \\
(\mathrm{nm})\end{array}$ & Porosity $(\%)$ \\
\hline 1 & 2311.5 & 97.0 & 58.69 \\
2 & 6852.3 & 126.3 & 44.16 \\
3 & 7725.8 & 72.7 & 46.44 \\
4 & 6839.5 & 77.6 & 49.74 \\
5 & 3951.3 & 317.8 & 50.46 \\
6 & 22743.4 & 621.1 & 52.59 \\
7 & 2172.9 & 1823.5 & 71.54 \\
\hline
\end{tabular}

The pore character is quite different. To the seven kinds of zeolites, the synthetic zeolite has the largest amount of pores which are distributed uniformly.

Moisture content. There is some water among the pores of zeolites. In natural condition, the water stays stable, but it will evaporate if temperature increases gradually. The water content of zeolites differs a lot. To analyze the evaporation of water, five specific temperatures $\left(105^{\circ} \mathrm{C}, 120^{\circ} \mathrm{C}\right.$, $140^{\circ} \mathrm{C}, 160^{\circ} \mathrm{C}$ and $180^{\circ} \mathrm{C}$ ) are selected and the result is in Table 3.

Table 3 Water content of zeolites

\begin{tabular}{cccccc}
\hline \multirow{2}{*}{ Zeolite } & \multicolumn{5}{c}{ Moisture loss under different temperature(\%) } \\
\cline { 2 - 6 } & $105^{\circ} \mathrm{C}$ & $120^{\circ} \mathrm{C}$ & $140^{\circ} \mathrm{C}$ & $160^{\circ} \mathrm{C}$ & $180^{\circ} \mathrm{C}$ \\
\hline 1 & 7.48 & 7.83 & 8.24 & 8.93 & 9.08 \\
2 & 5.45 & 5.52 & 5.52 & 5.52 & 5.53 \\
3 & 9.36 & 9.93 & 10.91 & 11.63 & 11.84 \\
4 & 8.73 & 8.92 & 9.65 & 10.02 & 10.49 \\
5 & 8.75 & 8.77 & 9.69 & 10.34 & 10.63 \\
6 & 4.20 & 4.28 & 4.91 & 4.92 & 4.94 \\
7 & 6.09 & 9.59 & 13.31 & 16.45 & 17.82 \\
Mineral & 0.43 & 0.43 & 0.43 & 0.44 & 0.44 \\
filler & & & & & \\
\hline
\end{tabular}


The amount of water which evaporates at different temperatures is quite different to these zeolites. No. 7 has the highest water loss while No. 6 has the lowest. But the water loss of zeolites is far more than limestone filler.

\section{Asphalt mixture design}

In AC-20 asphalt mixture, pen70 asphalt and limestone aggregates are used. In order to analyze the influence of zeolite on the properties of warm mix and to decrease the deviation of grading, all the aggregates are sieved in advance and then blended according to the target gradation of AC-20 mixture, which is in Table 4.

Table 4 Gradation of AC-20 asphalt mixture

\begin{tabular}{lcccccccccccc}
\hline Sieves(mm) & 26.5 & 19 & 16 & 13.2 & 9.5 & 4.75 & 2.36 & 1.18 & 0.60 & 0.30 & 0.15 & 0.075 \\
\hline Passing (\%) & 100 & 95.0 & 83.0 & 72.0 & 57.0 & 38.0 & 26.0 & 18.0 & 13.0 & 9.0 & 6.5 & 5.0 \\
Range (\%) & 100 & $90-100$ & $76-90$ & $64-80$ & $50-64$ & $33-43$ & $21-31$ & $13-23$ & $9-17$ & $6-12$ & $4-9$ & $3-7$ \\
\hline
\end{tabular}

Asphalt ratio. By volumetric analysis of the compacted Marshall specimens, the optimal asphalt ratio is $4.3 \%$. To hot and warm mix, the asphalt ratio differs little.

\section{Compacting properties of warm mixture}

Compaction is the most critical means to improve the integrity and the stability of asphalt mixture. The composition of the mixture, the properties of the aggregates and the rheological characteristics of the binder influence the compacting $[4,5,6]$. As to warm mixture, it must exhibit satisfying compacting ability at relatively low temperature. In this paper, the compacting behaviors of all the seven zeolites mixture are investigated. Table 5 is the compacting results of Aspha-min warm mixture and Table 6 is the air void of Marshall specimens. Table 7 shows the gyratory compacting results of the mixtures.

Table 5 Marshall compacting results of Aspha-min mix

\begin{tabular}{cccccc}
\hline \multirow{2}{*}{ Type } & $\begin{array}{c}\text { Mixing temperature } \\
\left({ }^{\circ} \mathrm{C}\right)\end{array}$ & $\begin{array}{c}\text { Compacting temperature } \\
\left({ }^{\circ} \mathrm{C}\right)\end{array}$ & $\mathrm{VV}(\%)$ & $\mathrm{VMA}(\%)$ & VFA(\%) \\
\hline Hot mix & 160 & 150 & 3.9 & 14.0 & 72.1 \\
Warm mix & 150 & 140 & 4.1 & 14.1 & 71.0 \\
& 140 & 130 & 4.3 & 14.3 & 69.9 \\
& 130 & 120 & 4.3 & 14.3 & 70.0 \\
& 120 & 110 & 4.8 & 14.8 & 67.6 \\
& 110 & 100 & 5.6 & 15.5 & 64.0 \\
& 100 & 90 & 6.5 & 16.3 & 60.1 \\
& 90 & 80 & 7.1 & 16.9 & 57.9 \\
\hline
\end{tabular}




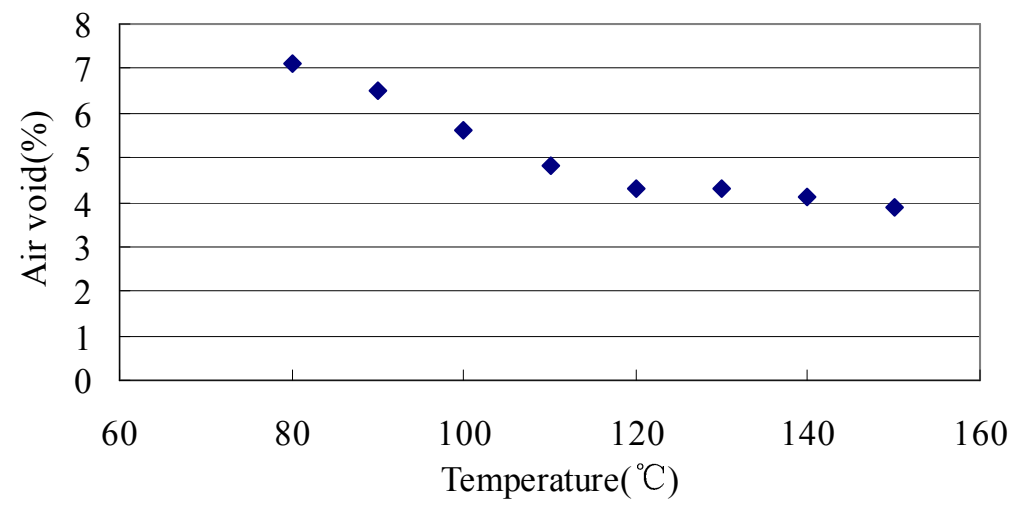

Figure1 Air void versus temperature

It is clear that to Aspha-min warm mixture, the air void of the mixture decreases with the increase of the compacting temperature as listed in Figure 1. There is a flat region in the compaction curve, which is between 120 to $140^{\circ} \mathrm{C}$. In this temperature span, the mixture is compactable and the mixture is not sensitive to temperature. If the compacting temperature is below $120^{\circ} \mathrm{C}$, the slope of the curve is steep and the mixture is sensitive to compacting temperature. It is suggested that to Aspha-min mixture, the compactable temperature is $120 \sim 140^{\circ} \mathrm{C}$.

Table 6 Air voids of Marshall compacting mixtures (\%)

\begin{tabular}{lccccc}
\hline Zeolite & Compact temp $\left({ }^{\circ} \mathrm{C}\right)$ & 110 & 120 & 130 & 140 \\
\hline 1 & & 5.0 & 4.5 & 4.5 & 3.8 \\
2 & 5.0 & 4.4 & 4.3 & 3.9 \\
3 & 5.2 & 4.4 & 4.4 & 4.3 \\
4 & 5.7 & 4.8 & 4.1 & 3.5 \\
5 & 5.0 & 4.4 & 4.1 & 4.0 \\
6 & 4.7 & 4.1 & 4.0 & 4.0 \\
& 7 & 4.8 & 4.3 & 4.3 & 4.1 \\
\hline
\end{tabular}

Table 7 Air voids of gyratory compacting mixtures (\%)

\begin{tabular}{ccccc}
\hline Zeolite & Compact temp $\left({ }^{\circ} \mathrm{C}\right)$ & 100 & 120 & 140 \\
\hline 1 & 5.2 & 3.8 & 3.4 \\
2 & 4.8 & 4.0 & 3.5 \\
3 & 4.6 & 3.9 & 3.3 \\
4 & 4.9 & 4.0 & 3.5 \\
5 & 5.0 & 4.2 & 3.2 \\
6 & 4.7 & 3.9 & 3.4 \\
7 & 4.4 & 4.1 & 3.0 \\
Hot mix & 5.4 & 4.8 & 4.0 \\
\hline
\end{tabular}




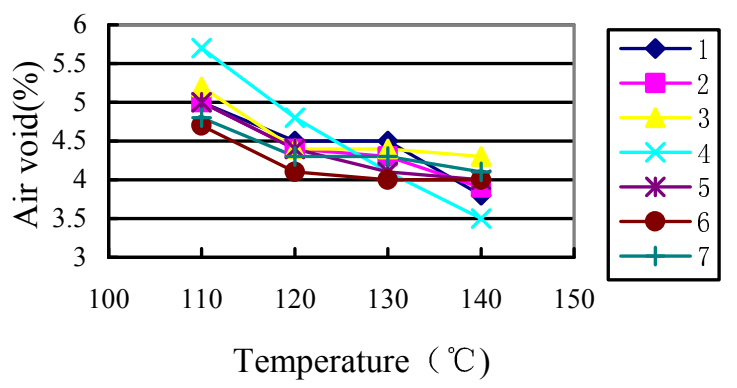

Figure 2 Air void of Marshall specimens

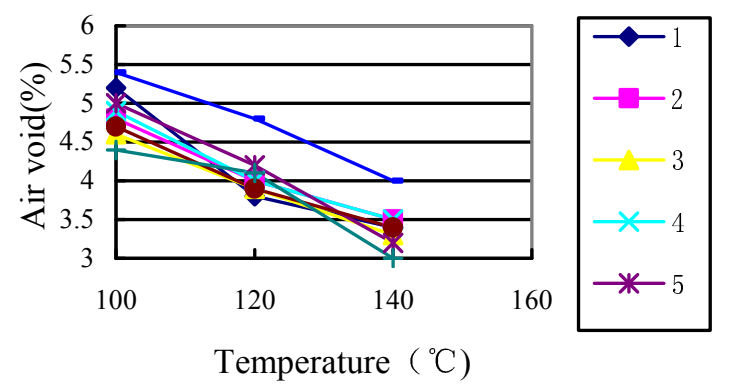

Figure 3 Air void of gyratory specimens

Marshall compaction result in Figure 2 shows that to different zeolites, the air void of the mixture is quite different. At the same temperature, No. 6 and No. 7 mixtures are easier to compact than the other five zeolites. No. 4 zeolite is most sensitive to temperature because the compacting curve is steep. Taking the pore structure into consideration, No.6 zeolite has the largest median pore diameter and No 7 has the largest average pore diameter. Pore diameter may influence the compacting effect. It is inferred that larger pores are helpful to the evaporation of the water and thus beneficial to the compaction.

The compacting curve of gyratory compacting specimens is Figure 3 and the comparison is Figure 4. Gyratory compaction specimens exhibit lower air voids. On the other hand, the air void of gyratory sample changes a little with the difference of zeolites, which means, gyratory compaction is less sensitive to the type of zeolites than Marshall compaction.

Hot mix is generally compacted at the temperature of $150^{\circ} \mathrm{C}$, and the target air void is $4.0 \%$. To keep the same level of air void, warm mix must be compacted no less than $120^{\circ} \mathrm{C}$ to all these zeolites. Compared to hot mix, the compacting temperature of zeolite based warm mix decreases about $30^{\circ} \mathrm{C}$.

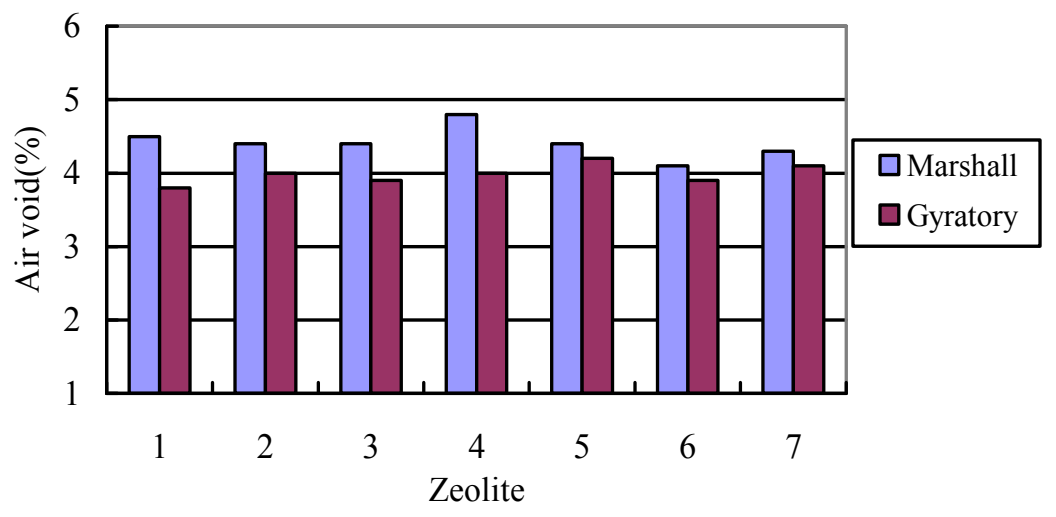

Figure 4 Air voids of Marshall and Gyratory specimens of $120^{\circ} \mathrm{C}$

\section{Conclusions}

In this paper, the properties of zeolites are evaluated and analyzed. The compaction of asphalt mixture is conducted and the following conclusions can be drawn:

Zeolite has smaller density than limestone filler. It is porous and some amount of water stays in the pores. The water evaporation of zeolite makes it useful in warm mixture. The pore structure and water contend differs with different zeolites. 
Temperature is the most important factor that influences compaction. With the increase of compacting temperature, the air void decreases. $120^{\circ} \mathrm{C}$ is the critical compactable temperature for zeolite mixture.

It is inferred that the pore diameter is one of the factors that affect the compaction.

Marshall compaction is more sensitive to the type of zeolites than gyratory compaction.

\section{Acknowledgements}

The authors appreciate the support of the Ministry of Science and Technology on the Research project of "Cooperative Research on Green Manufacturing Technology for Asphalt Pavement" (2010DFB83490).

\section{References}

[1] Qin Yongchun, Huang Songchang. Warm Asphalt Pavement Technologies and latest Researches [J]. Petroleum Asphalt, 2006.8, Vol20(4): 18-20

[2] M. Carmen Rubio, Germán Martínez, Luis Baena, Fernando Moreno. Warm mix asphalt: an overview. Journal of Cleaner Production 24 (2012) 76 84

[3] LIU Yu xin. Measurement and Expression of Pore Structure of Particle Material. China Powder Science and Technology. 2000.8.Vol 6 No 4:1-27

[4] Shen Jin'an. Performance of Asphalt and Asphalt Mixture[M]. China Commnication Press, 2001.5

[5] Ji Jie. Performance Evaluation of Recycled Asphalt Mixture and Warm Asphalt Mixture [M]. China Communications Press, 2011.5

[6] ZHANG Jiu-peng, PEI Jian-zhong, XU Li, XING Xiang-yang. Gyratory compaction characteristic of SBS warm mixed asphalt mixture. Journal of Traffic and Transportation Engineering.Vol11(1).2011.2;1 6

[7] SUN Ji-shu, XIAO Tian, YANG Chun-feng, JIN Can-zhang.On Properties of Warm Mix Recycled Asphalt Mixture in Highway JOURNAL OF CHONGQING JIAOTONG UNIVERSITY(NATURAL SCIENCE). 2011.4. Vo.1 30( 4).:259-253

[8] ZUO Feng, YE Fen. Evaluation on the technology and performances of warm mix asphalt mixture in foreign countries[J]. Chinese Journal of China \& Foreign Highway.2007.27 (6): 164-168. 